\title{
Complementary saphenous grafting: Long-term follow-up
}

\author{
Robert Dion, MD \\ David Glineur, MD \\ David Derouck, MD \\ Robert Verhelst, MD \\ Philippe Noirhomme, MD \\ Gebrine El Khoury, MD \\ Etienne Degrave, MD \\ Claude Hanet, MD, PhD
}

Objective: Recently we reviewed the 10-year clinical and angiographic outcomes of sequential internal thoracic artery grafting. Most of the patients also received complementary saphenous grafts, and their overall long-term patency rates were surprisingly high. Therefore, we decided to analyze these results in more detail.

Methods: The first consecutive 500 patients having received at least one sequential internal thoracic artery graft between October 1985 and August 1991 were restudied retrospectively. The saphenous grafts were only used to achieve complete revascularization in addition to complex arterial grafting on less significant or remote coronary vessels. A total of 161 patients consented to a late angiographic restudy at a mean postoperative interval of 7.5 years (1-12.2 years).

Results: At 5 and 10 years postoperatively, freedom from angina was $96 \%$ and $82 \%$, and freedom from any cardiac event was $92.8 \%$ and $69 \%$, respectively. Only $15(3.1 \%)$ patients needed additional revascularization ( $0.3 \%$ per patient-year): 4 coronary artery bypass grafting $(0.8 \%)$ and 11 percutaneous transluminal coronary angioplasty (2.3\%). The overall patency and intactness rates of saphenous anastomoses were $72.5 \%$ and $60.2 \%$, respectively. There was a significant difference between the patency and intactness of sequential versus single anastomoses: $76 \%$ versus $60 \%$ and $64.5 \%$ versus $44.4 \%$, respectively. There was no significant difference in either patency or intactness between right internal thoracic and sequential saphenous grafts anastomosed to the right coronary artery: $83.4 \%$ versus $75.2 \%$ and $77.8 \%$ versus $62.4 \%$, respectively. The same was true for the anastomoses to the "remote area" (distal circumflex, distal right coronary artery).

Conclusions: Complementary sequential saphenous grafting still deserves consideration in some patients below 70 years of age, particularly for those with disease in the "remote area": the distal circumflex and right coronary branches. received Feb 16, 2001; accepted for publication Feb 28, 2001.

Address for reprints: Robert Dion, MD, Academisch Ziekenhuis Leiden, Thoraxchirurgie K6S, Albinusdreef 2, 2333 ZA Leiden, The Netherlands (E-mail: r.a.e.dion@lumc.nl).

J Thorac Cardiovasc Surg 2001;122:296-304

Copyright (ㅇ 2001 by The American Association for Thoracic Surgery

$0022-5223 / 2001 \$ 35.00+0 \quad \mathbf{1 2 / 6 / 1 1 5 4 1 9}$

doi:10.1067/mtc.2001.115419

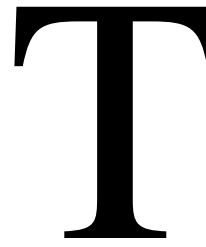

he long-term patency rate of internal thoracic artery (ITA) grafts has been proved far superior to that of saphenous vein grafts. ${ }^{1,2}$ Technical developments, such as sequential and bilateral grafting, and the use of free ITA grafts have allowed a total arterial revascularization in selected patients. ${ }^{3-8}$ However, complementary saphenous grafts are still frequently needed to achieve complete myocardial revascularization.

Recently, we ${ }^{6}$ reported the long-term clinical and angiographic follow-up of the first consecutive 500 patients having received at least one sequential ITA graft at the Cliniques Universitaires Saint-Luc in Brussels. Most of these patients had also 
TABLE 1. Grafts and anastomoses

\begin{tabular}{|c|c|c|c|}
\hline Grafts & & & 392 \\
\hline Single & & $147(37.5 \%)$ & \\
\hline Sequential & & 245 & \\
\hline Two anastomoses & 134 & & \\
\hline Three anastomoses & 77 & & \\
\hline Four anastomoses & 28 & & \\
\hline Five anastomoses & 5 & & \\
\hline Six anastomoses & 1 & & \\
\hline Anastomoses & & & 789 \\
\hline Single & & 147 & \\
\hline Sequential & & $642(81.4 \%)$ & \\
\hline
\end{tabular}

received complementary saphenous grafts, and angiographic restudy has revealed surprisingly high overall long-term patency rates of these saphenous grafts. Therefore, we decided to analyze these results in more detail.

\section{Patients and Methods}

The first consecutive 500 patients having received at least one sequential ITA graft between October 1985 and August 1991 were restudied retrospectively. There were $422(84 \%)$ men. Age averaged 61 years (25-87 years). A total of 117 (23\%) procedures were not elective and $35(7 \%)$ were reoperations. Two hundred forty-one (48\%) patients had had a previous myocardial infarction, $56(11 \%)$ had diabetes, 120 (24\%) were obese (body mass index > 25), 14 (3\%) had chronic obstructive pulmonary disease (forced expiratory volume in 1 second $\leq 1.5)$, and $12(2.4 \%)$ had severe renal insufficiency (serum creatinine $>2 \mathrm{mg} / \mathrm{dL}$ ).

\section{Patient Selection}

As previously described, ${ }^{3-6}$ no contraindications to the use of a single ITA graft existed aside from extreme chest deformities, severe disease of the subclavian arteries, severe disease of the ITA arteries, and catastrophic emergencies. However, insulin-dependent diabetes, advanced physiologic age, severe chronic obstructive pulmonary disease, obesity, nonviable myocardium, and acute evolving myocardial infarction were regarded, in our institution, as either relative or absolute contraindications to the use of bilateral ITA grafting, depending on their mode of presentation or association. A patient less than 70 years of age normally benefited from complex arterial grafting, whereas a patient more than 70 years of age had to somehow "deserve" it.

Therefore, venous grafting was merely used to complete the arterial revascularization. In patients younger than 70 years, every effort was made to achieve a complete arterial revascularization, the venous grafts being directed to "out of reach," less dominant vessels. In most of these situations, single grafts were used.

In patients older than 70 years of age, with heavy comorbid disorders and an expected decreased survival, the anterior wall was revascularized with ITA grafts, and venous grafts were used for the posterior and inferior walls. In this situation, most of these venous grafts were sequential. Therefore, sequential grafting was somewhat improved by this strategy, because of the relatively better quality of the target vessels.
TABLE 2. Destination of the anastomoses

\begin{tabular}{llr}
\hline & \multicolumn{1}{c}{ Total } & \multicolumn{1}{c}{ Sequential } \\
\hline LAD & $86(10.7 \%)$ & $73(11.2 \%)$ \\
Circumflex & $340(43.2 \%)$ & $292(45.6 \%)$ \\
RCA & $363(46.1 \%)$ & $277(43.2 \%)$ \\
Total & 789 & 642 \\
\hline
\end{tabular}

$L A D$, Left anterior descending coronary artery; $R C A$, right coronary artery.

\section{Preoperative Cardiac Catheterization}

Triple vessel disease was found in $281(56 \%)$ patients. The left ventricular ejection fraction estimated in a right anterior oblique $\left(30^{\circ}\right)$ view was less than 0.40 in $53(11 \%)$ cases. Routine preoperative angiographic assessment of both ITAs was required.

\section{Operative Technique}

The techniques of ITA and saphenous vein harvesting and preservation, as well as the techniques of ITA and saphenous anastomoses, have been described previously. 3,5,9 The saphenous grafts were mostly harvested below the knee, by means of a strictly notouch technique, and were gently flushed with heparinized blood to which papaverine $(40 \mathrm{mg} / 150 \mathrm{~mL})$ and dipyridamole $(20$ $\mathrm{mg} / 150 \mathrm{~mL}$ ) were added. The "parachute" technique with a running stitch of 7-0 polypropylene suture was used for all the venous anastomoses. In all, 1152 grafts corresponding to 2156 anastomoses (4.3 per patient, maximum 7 ) were constructed. There were 1367 arterial anastomoses ( 2.7 per patient) and 243 bilateral ITA grafts. There were 392 saphenous grafts corresponding to 789 anastomoses (1.6 per patient, maximum 6), of which $642(81.4 \%)$ were constructed in a sequential fashion (Table 1). Nearly all the sequential venous anastomoses were performed in a diamondshaped fashion and all of the single grafts in a parallel fashion. As expected, the majority $(89.3 \%)$ of these anastomoses were directed to the circumflex $(43.2 \%)$ and to the right coronary artery (RCA) $(46.1 \%)$ areas. Only $86(10.7 \%)$ were made to the left anterior descending (LAD) area (Table 2).

Systemic hypothermia and intermittent cold crystalloid ( $\mathrm{St}$ Thomas' Hospital) cardioplegia with topical cooling was used in all cases as described previously. The duration of cardiopulmonary bypass averaged 116 minutes and aortic crossclamp time, $70 \mathrm{~min}-$ utes.

\section{Follow-up}

Clinical follow-up was obtained by recalling the patients for an ambulatory examination, by telephonic contact, or by written questionnaires sent to patients, general practitioners, and cardiologists.

A total of 161 patients consented to a late angiographic restudy after a mean postoperative interval of 7.5 years (1-12.2 years).

\section{Statistical Methods}

Simple comparison of proportions was made with the Fisher exact test. So that adjustments could be made for potential confounding factors, multivariate analysis by means of logistic regression was performed, with influential effects of the following factors being taken into account: age at operation, sex, obesity, dyslipidemia, diabetes, arterial hypertension, smoking, and renal insufficiency. 
TABLE 3. Late iterative revascularizations: $15=3.1 \%$ at 9.6 years

\begin{tabular}{lcc}
\hline Vessel (graft) & New graft & Postop interval (mo) \\
\hline CABG: $4=0.8 \%$ & & \\
LAD (RITA) & IEA & +80 \\
LAD (LITA) & RITA & +106 \\
PDA (RITA) & RGEA & +34 \\
PDA (SVG) & RGEA & +136 \\
PTCA: $11=2.3 \%$ & & \\
Grafts $(\mathrm{n}=6)$ & \\
SVG & $5(\mathrm{CX}=4 ;$ PDA $=1)$ \\
ITA (free) & 1 (CX) \\
Coronary vessels $(\mathrm{n}=5)$ & \\
Grafted & 1 (CX) \\
Ungrafted & 4 (RCA) & \\
\hline
\end{tabular}

$\overline{C A B G \text {, Coronary artery bypass graft; PTCA, percutaneous transluminal }}$ coronary angioplasty; $L A D$, left anterior descending artery; $P D A$, posterior descending artery; SVG, saphenous vein graft; IEA, inferior epigastric artery; $R I T A$, right internal thoracic artery; $R G E A$, right gastroepiploic artery; $C X$, circumflex artery.

Possible interactions between influential factors were also investigated. Results are expressed in terms of odds ratios (OR) with $95 \%$ confidence intervals (CI). For the statistical tests, focus was put on the patency of the anastomoses. Statistical software SPSS (SPSS, Inc, Chicago, Ill) was used.

\section{Results \\ Early Complications and Deaths}

Hospital mortality. Eight (1.6\%) patients died during their hospital stay, 3 of them of a cardiac cause. The other causes were multiorgan failure in 2 patients, fulminant gastrointestinal bleeding in 2, and ischemic colitis in 1.

Early complications. Seventeen (3.4\%) patients needed marked inotropic support ( $\geq 5 \gamma$ dobutamine or dopamine), and $2(0.4 \%)$ patients needed that inotropic support for more than 24 hours.

A reoperation was necessary for postoperative bleeding in $18(3.6 \%)$ patients, for persistent myocardial ischemia in $7(1.4 \%)$, and for sternal dehiscence in $6(1.2 \%), 2$ of them due to infection.

Perioperative myocardial infarction, defined by enzymatic elevation (aspartate aminotransferase $\geq 100 \mathrm{U} / \mathrm{L}$ ) and/or electrocardiographic alteration, was diagnosed in 18 (3.6\%) patients, with hemodynamic deterioration in 2 .

\section{Follow-up}

Follow-up was $97.4 \%$ complete (487 patients) and averaged 9.6 years (8.6-13.6 years).

As recently reported, ${ }^{6}$ the Kaplan-Meier curves, 5 and 10 years postoperatively, show a cumulated survival of $89 \%$ and $72 \%$, a freedom from angina of $96 \%$ and $82 \%$, a freedom from any ischemia (angina, silent ischemia, myocardial infarction, and cardiac death) of $93.6 \%$ and $71 \%$, and a free- dom from any cardiac event (ischemia, revascularization, transplantation, and death) of $92.8 \%$ and $69 \%$, respectively.

Overall, only $15(3.1 \%)$ patients needed additional revascularization over the entire follow-up, an incidence of $0.3 \%$ per patient-year. Eleven $(2.3 \%)$ patients benefited from a percutaneous transluminal coronary angioplasty and $4(0.8 \%)$ patients from coronary artery bypass grafting (Table 3).

\section{Angiographic Results}

A total of 161 patients consented to a repeat catheterization at an average of 7.5 years (1-12.2 years) after the operation. All the angiographic restudies were reviewed separately by a cardiologist and a surgeon. All the comparisons have been made after adjustment for potential confounding factors as mentioned above (multivariate analysis using logistic regression).

Overall angiographic patency. The overall angiographic patency rates of the arterial and saphenous vein anastomoses are illustrated in Figure 1. A patent anastomosis is called "intact" when no narrowing at all can be seen at angiographic restudy.

There is, of course, a striking difference between the overall patency and intactness rates of arterial versus saphenous anastomoses: $95.5 \%$ versus $72.5 \%(\mathrm{OR}=9.6$; $95 \%$ $\mathrm{CI}=5.3-17.1 ; P<.001)$ and $93.5 \%$ versus $60.2 \%$ $(P<.001)$, respectively. The same applies between sequential ITA and sequential saphenous anastomoses: $96.1 \%$ versus $76 \%(\mathrm{OR}=8.3 ; 95 \% \mathrm{CI}=4.3-16.2 ; P<.001)$ and $94.7 \%$ versus $64.5 \%(P<.001)$. There is also a noteworthy significant difference between the patency and intactness rates of sequential versus single saphenous anastomoses: $76 \%$ vs $60 \%(\mathrm{OR}=2.2 ; 95 \% \mathrm{CI}=1.1-4.6 ; P<.04)$ and $64.5 \%$ versus $44.4 \%$, respectively.

Patency rates of free ITA grafts and saphenous grafts. Because of the rather mediocre patency rates of our free ITA grafts when we were connecting them to the ascending aorta in our initial experience, ${ }^{8}$ we thought it useful to compare their patency rates with those of saphenous grafts (Figure 2). There was no significant difference between the overall patency rates of free ITA anastomoses and of saphenous grafts, although the free ITAs were significantly more intact.

More surprising, there was no significant difference in patency and intactness rates between free ITA anastomoses and sequential saphenous anastomoses: $80 \%$ versus $76 \%$ and $80 \%$ versus $65 \%$. However, the power of this comparison is less than $40 \%$ because of the small numbers of anastomoses.

Patency correlated with grafted coronary area (Figure 3). The patency and the intactness of the saphenous anastomoses did not differ significantly when correlated with the LAD, circumflex, and RCA areas $(P=.2$, logistic regres- 
RESTUDIED

ARTERIAL **

Single

Sequential ITA

Total

SAPHENOUS

Single

Sequential

Total

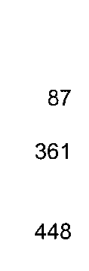

448

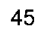

166

211
PATENT

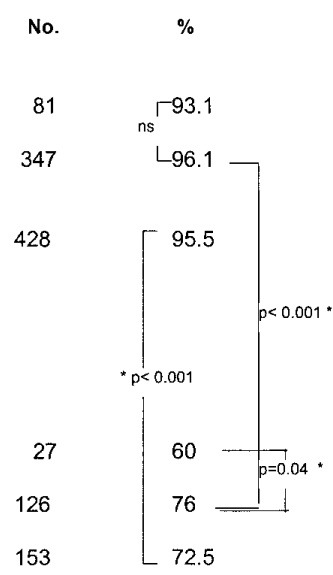

INTACT

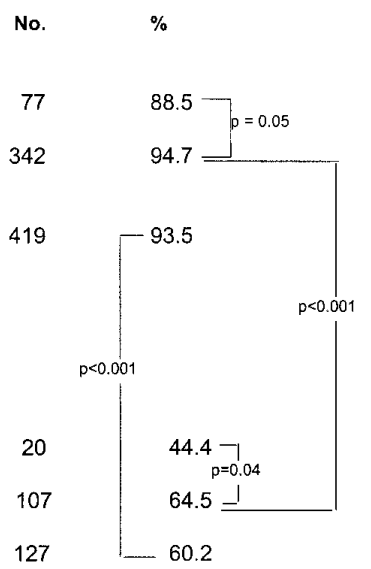

Figure 1. Angiographic patency of arterial and saphenous anastomoses 7.5 years postoperatively. ITA, Internal thoracic artery; GEA, right gastroepiploic artery; IEA, inferior epigastric artery. *After adjustment for risk factors (see text). **441 ITA, 6 GEA, and 1 IEA graft.

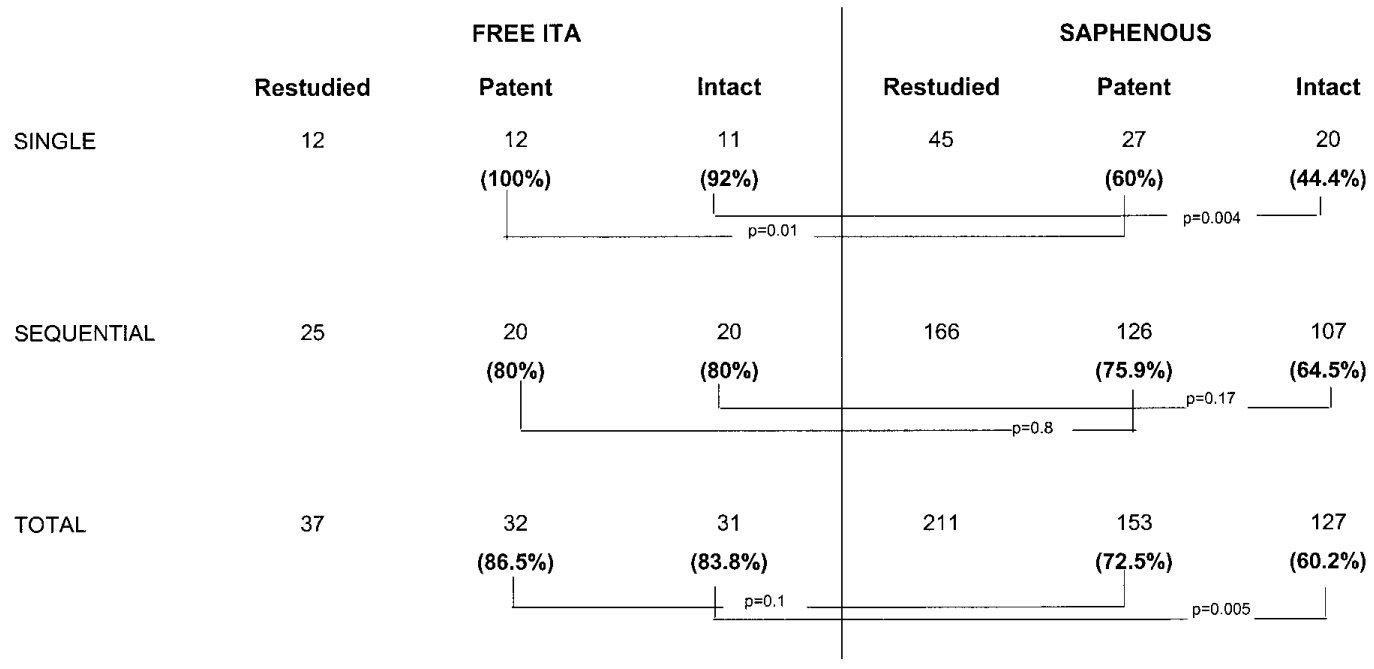

Figure 2. Patency of saphenous versus free ITA grafts at 7.5 years.

sion), even though there seemed to be an advantage for LAD anastomoses:

Circumflex versus LAD: $P=0.2$ (OR 0.1-1.56; CI 95\%)

Circumflex plus RCA versus LAD artery: $P=.6$

$$
\text { (OR 0.5-7.8; CI 95\%) }
$$

Patency of proximal versus distal sequential saphenous anastomoses. There was no difference between the patency and the intactness rates of the proximal and the distal anastomoses: $76 \%$ versus $76 \%$ and $63.2 \%$ versus $66.2 \%$, respectively.

Diabetes and patency (Figure 4). Diabetes had no significant deleterious influence, except maybe a trend on the intactness of sequential anastomoses: $51.6 \%$ versus $67.4 \%(P=.1)$.

Patency of right ITA grafts. Because of the disappoint- ing patency rates of our pedicled right ITA grafts anastomosed to the distal RCA, ${ }^{3,4}$ we compared their patency rates with those of saphenous grafts (Figure 5). Overall, there was no significant difference in either patency or intactness: $83.4 \%$ versus $75.2 \%(P=.5)$ and $77.8 \%$ versus $62.4 \%(P=.3)$. Here again, as for Figure 2, the power of the comparison hardly reaches $50 \%$ because of the small number of anastomoses. Only the intactness of single saphenous grafts was significantly lower: $43.3 \%$ versus $85.7 \%(P=.01)$.

Comparison of the patency rates of arterial versus saphenous anastomoses in the "remote area": distal circumflex and RCA (Figure 6). Here again, only the single saphenous anastomoses fare significantly worse than the 
RESTUDIED

19

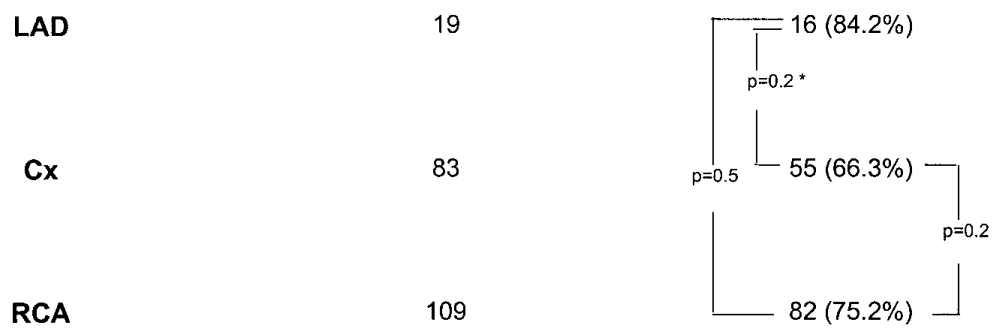

INTACT

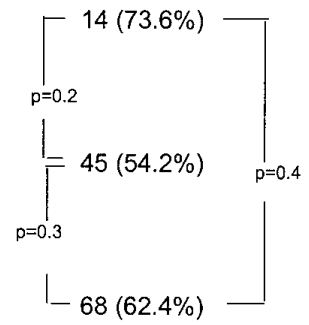

Logistic regression $p=0.2$

Figure 3. Patency per area of grafted vessels 7.5 years postoperatively. *After adjustment for risk factors (see text).

NO DIABETES

Restudied

Patent

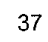

Single

Sequential

TOTAL
135

172
Intact

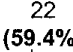

16

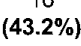

Restudied NS
31

22

(62.5\%)

$(71 \%)$

27

$(69.2 \%)$
DIABETES

Patent Intact

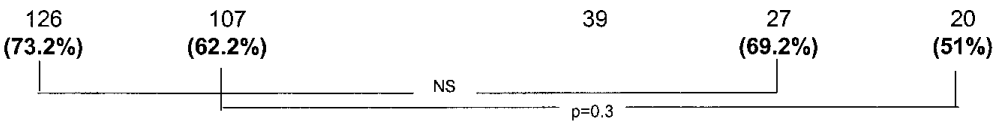

Figure 4. Diabetes and patency of saphenous vein anastomoses at 7.5 years, after adjustment for risk factors (see text).

arterial ones $(\mathrm{OR}=7.4 ; 95 \% \mathrm{CI}=1.5-36.8 ; P=.01$; sequential anastomoses: $\mathrm{OR}=1.4 ; 95 \% \mathrm{CI}=0.3-6.9$ ).

\section{Discussion}

Keeping in mind that we report on complementary saphenous grafting, to less significant or remote coronary vessels, the overall patency rates of the saphenous anastomoses are unexpectedly high $(72.5 \%$ patency and $60 \%$ intactness at 7.5 years) if we compare them with those found in other series ${ }^{1,2,10-12}$ (patency, 60\%-80\%; intactness, $52 \%-62 \%)$ at 10 years. Indeed, in these series, the saphenous grafts were distributed over the whole myocardium, and the patency rates are those of the grafts and not of the anastomoses. It is also noteworthy that these patency rates have only worsened by $10 \%$ in 7 years. ${ }^{3,4}$ These results are due to the excellent outcome of sequential saphenous grafting: $76 \%$ patency and $64.5 \%$ intactness. We believe that the quality of our harvesting and preservation, resulting in better protection of the endothelium and of its epoprostenol (prostacyclin) production, ${ }^{9}$ and the superior flow obtained after sequential grafting ${ }^{13}$ are the clues to this surprising outcome. Indeed, a double sequential coronary artery bypass graft has nearly half the coronary vascular resistance of a single bypass graft, ${ }^{13}$ and the prominent feature of the velocity profile just proximal to the side-to-side anastomosis in the sequential venous graft was the skewing of the profile toward the anastomosis side wall, suggesting high velocity into the anastomosed vessel. ${ }^{14}$ As mentioned above, sequential venous grafts have also been somewhat improved in our series by our grafting strategy. Finally, to allow adjustment for potential confounding factors, multivariate analysis by means of logistic regression was performed. Influential effects of the following factors were taken into account: age at operation, sex, obesity, dyslipi- 


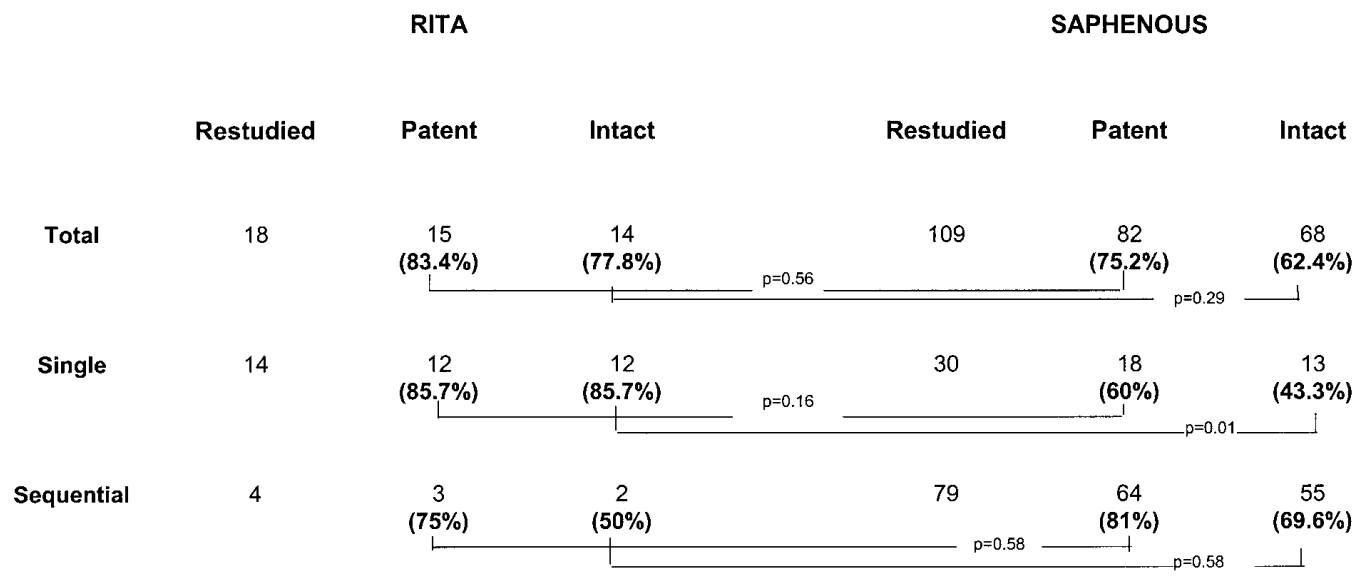

Figure 5. RCA: patency of right ITA versus saphenous anastomoses at 7.5 years.

ARTERIAL

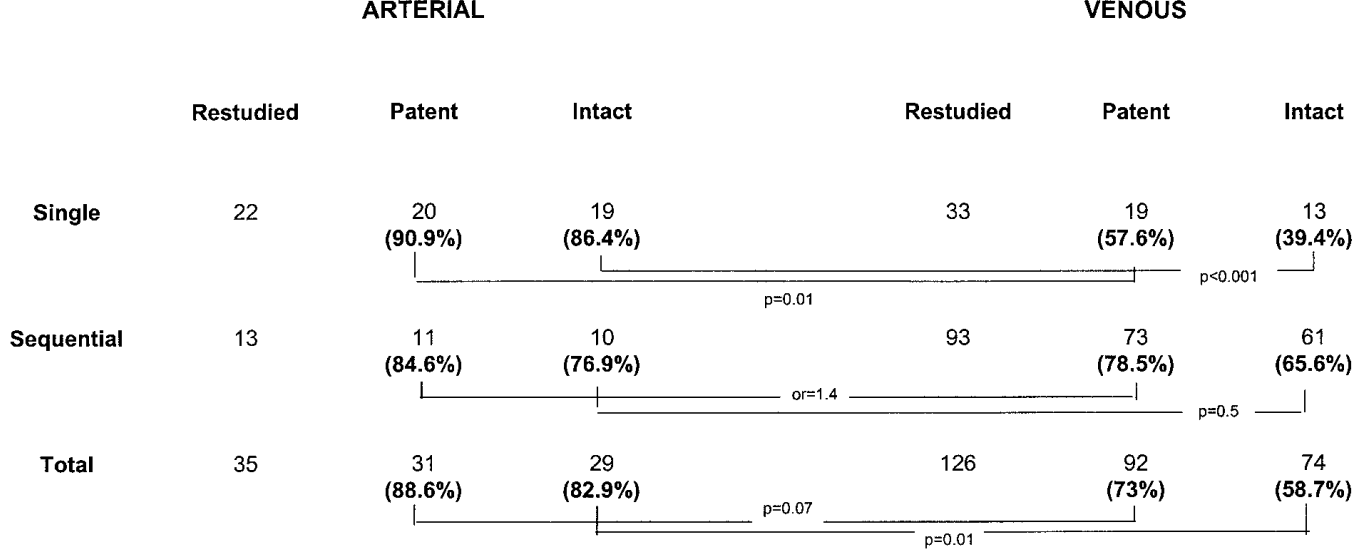

Figure 6. Distal circumflex and RCA: patency of saphenous versus arterial anastomoses at 7.5 years, after adjustment for risk factors.

demia, diabetes, arterial hypertension, smoking, and renal insufficiency.

Since their first introduction by Flemma, Johnson, and Lepley, ${ }^{15}$ sequential venous grafts have usually been demonstrated to retain their patency longer than single grafts, ${ }^{10,12,13,16-19}$ even more so if the most distal anastomosis is constructed to the coronary vessel with the highest flow.

Should we then modify our global strategy of aggressive arterial revascularization? Certainly not in patients less than 70 years of age who are not crippled by severe comorbid disorders. Indeed, only $60 \%$ of all the saphenous anastomoses and $64.5 \%$ of the sequential ones are intact at 7.5 years, compared with $94 \%$ and $95 \%$ for the arterial ones, respectively (Figure 1): the ongoing attrition rate of the saphenous grafts remains a source of concern. Fitzgibbon and associates ${ }^{20}$ reported the "7.5-year phenomenon": an unexpected increase in vein graft abnormality after 5 years. The actual rate of reoperations increased significantly 5 years after the first coronary artery bypass graft, plateaued at 10 to 14 years, then decreased to a lower but steady level. ${ }^{11}$ Pick and associates ${ }^{21}$ found that occlusion or significant stenoses of preexisting saphenous grafts led to recurrent ischemia in $96 \%$ of the patients having undergone a third or a fourth operation for myocardial ischemia. Lytle and colleagues ${ }^{22}$ clearly revealed the negative clinical impact of stenoses in saphenous grafts on reoperative outcome.

Here, complementary venous grafting was responsible for only 1 of the 4 repeat bypass graft operations and 5 of the 11 angioplasties (Table 3), which validates our global revascularization strategy. As recently reported, ${ }^{6}$ only 15 (3.1\%) patients needed additional revascularization over the entire follow-up, an incidence of $0.3 \%$ per patient-year. 
However, the type of grafts to be used in the "remote area" (distal circumflex/RCA) deserves to be thoughtfully discussed. Indeed, as found by others, ${ }^{23-25}$ our patency rates of pedicled right ITA anastomoses to the distal RCA were less satisfactory (83.3\%), as were those of all ITA anastomoses to the very distal circumflex and RCA: $88.6 \%$. As reported before, ${ }^{3-5}$ we have restricted the use of pedicled right ITA grafts to the proximal RCA before the acute margin of the heart-with much improved patency rates (95\% at 13 months $^{2,3}$ ) - and we preferred to use right gastroepiploic arteries for grafting the distal RCA: $91 \%$ patency at 13 months. ${ }^{26}$ With regard to the "remote area," in patients less than 70 years of age without severe comorbid disorders, we now use the right gastroepiploic artery, the free right ITA in a T or Y connection with the pedicled left ITA ${ }^{5-7,15}$ (in our experience [unpublished data] the early patency of this construction is identical to that of the pedicled ITA to LAD and circumflex arteries [95\%]), or the pedicled left ITA. These 3 alternatives have their limitations. The use of the right gastroepiploic artery is contraindicated in patients with disease of the descending aorta and in those in whom the RCA is dominant and not severely narrowed ${ }^{26}$; it is not easy for sequential grafting and after previous abdominal operations. T or Y ITA grafting is technically more demanding, puts "all eggs in one basket," and is not advisable when the left ITA is not well developed. The pedicled left ITA does not always reach the distal branches of the RCA, and the very distal segment of the ITA is known to be more muscular and less resistant to atherosclerosis.

In light of the surprisingly favorable long-term patency rates of sequential saphenous grafting (Figure 6) in this area, its use may be warranted in some patients of the "younger" group. The use of the radial artery graft might also be considered. Acar ${ }^{27}$ reported an $84 \%$ patency at 5 years. Will the radial artery retain a significantly better patency than the sequential saphenous grafts in these grafting circumstances at a mean postoperative interval of 7.5 years? Besides, we still consider harvesting of the radial artery to be more invasive than harvesting of the saphenous grafts.

In sequential saphenous grafting, as for ITA grafting, ${ }^{6}$ we found no difference in patency between the various distal anastomoses, unlike Grondin and Limet ${ }^{19}$ and Kieser, Fitzgibbon, and Keon, ${ }^{12}$ who described a clear superiority of the side-to-side anastomoses over the distal end-to-side ones. Nearly all the sequential venous anastomoses were performed in a diamond-shaped fashion and all of the single venous grafts in a parallel fashion: the diamond-shaped anastomoses certainly fare better than the parallel ones, but the comparison is totally biased.

In our series, insulin-dependent diabetes did not significantly alter the long-term patency of saphenous anasto- moses, even after adjustement for potential confounding factors, which is also a surprise.

Eighty-four percent of the patients were still asymptomatic, and $71 \%$ were free of any type of ischemia at 10 years. At 5 and 10 years, $92.8 \%$ and $69 \%$ of the patients remained free of any cardiac event (ischemia, revascularization, transplantation, and cardiac death).

The thoughtful combination of complex arterial grafting and of complementary saphenous grafting (preferably sequential and particularly in the "remote area") has been rewarding because it has provided our patients an excellent clinical outcome and an extremely low need for repeat revascularization.

\section{References}

1. Campeau L, Enjalbert M, Lespérance J, Vaislic C, Grondin CM, Bourassa MG. Atherosclerosis and late closure of aortocoronary saphenous vein grafts: sequential angiographic studies at 2 weeks, 1 year, 5 to 7 years, and 10 to 12 years after surgery. Circulation. 1983;68(Suppl):II-1-7.

2. Lytle BW, Loop FD, Cosgrove DM, Ratliff NB, Easlay K, Taylor PC. Long-term ( 5 to 12 years) serial studies of internal mammary artery and saphenous vein coronary bypass grafts. J Thorac Cardiovasc Surg. 1985;89:248-58.

3. Dion R, Verhelst R, Rousseau M, Goenen M, Ponlot R, KestensServaye $Y$, et al. Sequential mammary grafting: clinical, functional, and angiographic assessment 6 months postoperatively in 231 consecutive patients. J Thorac Cardiovasc Surg. 1989;98:80-9.

4. Dion R, Etienne PY, Verhelst R, Khoury G, Rubay J, Bettendorff PH, et al. Bilateral mammary grafting. Eur J Cardiothorac Surg. 1993;7:287-94.

5. Dion R. Complete arterial revascularization with the internal thoracic arteries. Oper Tech Card Thorac Surg. 1996;1:84-107.

6. Dion R, Glineur D, Derouck D, Verhelst R, Noirhomme P, El Khoury $\mathrm{G}$, et al. Long-term clinical and angiographic follow-up of sequential ITA grafting. Eur J Cardiothorac Surg. 2000;17:407-14.

7. Tector AJ, Amundsen S, Schmahl TM. Total revascularization with Y grafts. Ann Thorac Surg. 1994;57:33-9.

8. Verhelst E, Etienne PY, El Khoury G, Noirhomme P, Rubay J, Dion R. Free internal mammary artery graft in myocardial revascularization. Cardiovasc Surg. 1996;4:212-6.

9. Dion R, Lavenne-Pardonge E, Scheiff JM, Verhelst R, Baele P, Moriau M. A novel preservation medium protecting prostacyclin production and endothelial integrity of the human saphenous vein graft. Thromb Res 1990;Suppl XII:81-6.

10. Christenson JT, Schmuziger M. Sequential venous bypass grafts: results 10 years later. Ann Thorac Surg. 1997;63:371-6.

11. Fitzgibbon GM, Kafka HP, Leach AJ, Keon WJ, Hooper GD, Burton JR. Coronary bypass graft fate and patient outcome: angiographic follow-up of 5065 grafts related to survival and reoperation in 1388 patients during 25 years. J Am Coll Cardiol. 1996;28:616-26.

12. Kieser TM, Fitzgibbon GM, Keon WJ. Sequential coronary bypass grafts: long-term follow-up. J Thorac Cardiovasc Surg. 1986;91:76772.

13. O’Neill MJ Jr, Wolf PD, O’Neill TK, Montesano RM, Waldhausen JA. A rationale for the use of sequential coronary artery bypass grafts. $J$ Thorac Cardiovasc Surg. 1981;81:686-90.

14. Fujiwara T, Kajiya F, Kanazawa S. Comparison of blood-flow waveforms in different coronary artery bypass grafts: sequential saphenous vein grafts and internal mammary artery grafts. Circulation. 1988;78:1210-7.

15. Flemma RJ, Johnson DW, Lepley D Jr. Triple artocoronary vein bypass as treatment for coronary insufficiency. Arch Surg. 1971;103:82-3. 
16. Grondin CM, Vouché P, Bourassa MG, Lespérance J, Bouvier M, Campean L. Optimal patency rates obtained in coronary artery grafting with circular vein grafts. J Thorac Cardiovasc Surg. 1978;75:161-6.

17. Grondin CM, Lespérance J, Bourassa MG, Campean L. Coronary artery grafting with the saphenous vein or internal mammary artery. Ann Thorac Surg. 1975;20:605-18.

18. Christenson JT, Simonet F, Schmuziger M. Sequential vein bypass grafting: tactics and long-term results. Cardiovasc Surg. 1998;6:389-97.

19. Grondin CM, Limet R. Sequential anastomoses in coronary artery grafting: technical aspects and early and late angiographic results. Ann Thorac Surg. 1977;23:1-8.

20. Fitzgibbon GM, Leach AJ, Kafka HP, Keon WJ. Coronary bypass graft fate: long-term angiographic study. J Am Coll Cardiol. 1991;17:107580

21. Pick AW, Mullany CJ, Orszulak TA, Daly RC, Schaff HV. Third and fourth operations for myocardial ischemia: short-term results and long-term survival. Circulation. 1997;96(Suppl):II-26-31.

22. Lytle BW, Loop FD, Taylor PC, Simpfendorfer C, Kramer JR, Ratliff $\mathrm{NB}$, et al. Vein graft disease: the clinical impact of stenoses in saphenous vein bypass grafts to coronary arteries. I Thorac Cardiovasc Surg. 1992;103:831-40.

23. Lytle BW, Blackstone EH, Loop FD, Houghtaling PL, Arnold JH, Akhrass R, et al. Two internal thoracic artery grafts are better than one. J Thorac Cardiovasc Surg. 1999;117:855-72.

24. Chow MST, Sim E, Orszulak TA. Patency of internal thoracic artery grafts: comparison of right versus left and importance of vessel grafted. Circulation. 1994;90(Suppl):II-129-32.

25. Dietl CA, Benoit CH, Gilbert CL, Woods EL, Pharr WF, Berkheimer $\mathrm{MD}$, et al. Which is the graft of choice for the right coronary and posterior descending arteries? Comparison of the right internal mammary artery and the right gastroepiploic artery. Circulation. 1995;92(Suppl):II-92-7.

26. Albertini A, Lochegnies A, El Khoury G, Verhelst R, Noirhomme P, Matta A, et al. Use of the right gastroepiploic artery as a coronary graft in 307 patients. Cardiovasc Surg. 1998;6:419-23.

27. Acar C, Ramsheyi A, Pagny JY, Jebara V, Barrier P, Fabiani JN, et al. The radial artery for coronary artery bypass grafting: clinical and angiographic results at five years. J Thorac Cardiovac Surg. 1998;116:981-9

\section{Discussion}

Dr Stephen E. Fremes (Toronto, Ontario, Canada). Dr Dion has summarized the late clinical and angiographic results of the first 500 consecutive patients who had sequential ITA grafting between October 1985 and August 1991. At a median of 7.5 years, 161 patients consented to repeat angiography, approximately $40 \%$ of the estimated number of surviving patients. The results pertaining to the sequential arterial grafts were published in the April 2000 issue of the European Journal of Cardiothoracic Surgery, and this presentation focuses on the ancillary findings related to sequential venous grafts.

The statistical analysis of graft patency data is complex, as patients usually have multiple grafts, and multiple grafts within each patient cannot be treated as independent observations. Rather, they are correlated. This problem is presumably compounded with the use of sequential grafts.

The richest source of graft patency data in the literature is derived from the various randomized studies of antithrombotic medications. Seven studies concerning almost 6000 venous anastomoses separated their findings according to single versus sequential status. The aggregate results from the active treatment arms demonstrated a small but significant reduction in early graft occlusion favoring sequential grafting $12.3 \%$ versus $14.2 \%$ (odds ratio $0.87, P=.04)$.

The average number of grafts per patient in this current study was 4.1, 2.8 arterial and 1.3 venous grafts per patient. The number of sequential venous grafts was much greater than the number of single grafts, 166 versus 45 , suggesting that sequential venous grafting was the preferred technique for saphenous veins in their institution.

The authors have made a number of subgroup comparisons. The total number of venous grafts and limited number of free ITA grafts mean that the various subgroups are correspondingly smaller. This restricts the power to identify a difference, should one exist.

The manuscript provides a great deal of description regarding their use of arterial grafts but much less detail about the use of saphenous grafts. Because of the retrospective nature of the study, it is difficult to identify the factors that determine the use of sequential versus single venous grafts, especially the size and quality of the venous conduit, size and quality of the coronary artery, and status of the myocardium that the graft subserves. Such potential confounders have been shown in other studies to affect patency.

Some additional issues could also influence results. Were there any inclusion-exclusion criteria for follow-up research angiography? How did they handle the angiographic data of the symptomatic patients who had a clinically directed angiogram or subsequent revascularization? Was the information included or excluded?

This is a very provocative paper, but we should not lose sight of the main message, which is that persistent patency of ITA grafts, including sequential grafts, far exceeded that of the venous grafts. Furthermore, the venous graft results, whether single or sequential, will probably only deteriorate with additional follow-up, whereas the ITA findings are presumably stable. There were a few specific ITA grafting situations in which sequential ITA results were less satisfactory and should probably be avoided. The authors alluded to alternative grafting strategies in these cases, and I would ask them to elaborate on whether they recommend sequential venous grafts in these situations or would they prefer radial, gastroepiploic, or T grafts, particularly when these are options for more distal coronary targets?

Are these findings generalizable? The results were obtained from a center with an excellent reputation for arterial grafting and follow-up angiography to assess the results. Furthermore, sequential grafting appeared to be the preferred strategy for saphenous veins in their institution, and possibly single grafts were used in unfavorable circumstances. Equivalent results may not be obtained in less experienced hands, and confirmatory results by other investigators would be helpful.

Dr Dion. Thank you, Dr Fremes, for the comments. Regarding the indications for angiography, we tried to restudy as many patients as we could, symptomatic or not-most of them were not symptomatic_-by telephoning the patients themselves, as well as the cardiologists and the general practitioners. There were no exclusion criteria, and the angiographic restudies of patients having benefited from a subsequent revascularization were included in this series. 
Your second point concerned the indication for saphenous grafts, be they simple or sequential. As mentioned earlier, the saphenous grafts were used to achieve complete revascularization in addition to complementing arterial grafting on less significant or remote coronary vessels - out of reach of pedicled arterial grafting-to complement single ITA grafting in patients not "deserving" bilateral ITA grafting. There was certainly no predetermined preference for sequential saphenous grafting, but complete revascularization was a prerequisite. The study is retrospective, but the indications and surgical techniques are certainly homogeneous as the operations have been performed by two surgeons and me, acting as supervisor.

The ITA results were indeed less satisfactory in a few specific grafting situations, such as in the "remote area": distal circumflex and RCA areas. At that time we did not use the gastroepiploic artery systematically. We were preferentially using pedicled bilateral ITA grafts for the anterior and posterior walls, but it was not often possible to reach the interior wall: hence, our rather frequent use of saphenous grafts in the "remote area." For this "remote area," the possibilities are pedicled left ITA, right gastroepiploic artery, T ITA graft, or saphenous grafts. The goal of this presentation is certainly not to promote the systematic use of sequential venous grafts in this area. However, taking into account their surprisingly good long-term results, they might be a suitable alternative to others in some patients, for instance, a 65-year-old patient with moderate chronic obstructive pulmonary disease, obesity, or previous abdominal surgery. Of course, in a patient less than 60 years old without any comorbid disorder, we would use arterial grafting: pedicled left ITA, T right ITA, or right gastroepiploic artery, the third option being considered by us as contraindicated in the presence of a dominant RCA with less than a $75 \%$ stenosis.

Dr Thomas Z. Lajos (Buffalo, NY). In 1983 we depicted the grafts without valves. We performed coronary bypasses with valveless veins and also with valvular veins. Our overall result was the same as yours, a 75\% patency with an average follow-up of 8 to 12 years. However, when one breaks down the valvular versus the valveless veins, the single graft carries a patency of $70.5 \%$ and the valveless single graft, $78.4 \%$. I would like to make a couple of points about the sequential grafts. Overall, the sequential grafts stayed patent in the highest incidence in the study period. The patency rate of the valveless sequential grafts was $88.6 \%$, and that of the valvular sequential grafts, $72 \%(P<.01)$.

Survival and patency of grafts are two different parameters. The survival is interestingly better with the single valveless grafts$81 \%$ in 12 years versus $70.9 \%$ in the sequential grafts. The second point about the sequential grafts is that if the patient will need invasive cardiologic intervention, angioplasty or stenting, in 10 to 15 years, the sequential grafts may create technical difficulty. A single graft is more amenable for angiographic intervention.

Dr Dion. Unfortunately, I cannot comment on your remark, because we did not prospectively split our venous grafts into "valveless" and "valved" ones. Indeed, through this period, we concentrated only on performing as many arterial anastomoses as possible. However, I would agree with you that if one has to use a saphenous graft, it is preferable to select a "valveless" segment. 